\title{
Progressive Muscle Relaxation: An adjuvant therapy for reducing pain and fatigue among hospitalized cancer patients receiving radiotherapy
}

\author{
Pragya Pathak*, Rajinder Mahal, Adarsh Kohli, Vinod Nimbran \\ Lecturer, National Institute of Nursing Education, Post Graduate Institute of Medical Education and Research, Sector-12, \\ Chandigarh. Pin-160012, India \\ Principal, Mohan Dai Oswal College of Nursing, Oswal Caner Hospital, Ludhiana, Pin-141009, Punjab, India \\ Professor, Department of Psychiatry, Post Graduate Institute of Medical Education and Research, Sector-12, \\ Chandigarh. Pin-160012, India \\ Head, Department of Radiation oncology, Grecian super speciality hospital, sector-69, Mohali,Pin-160062, Punjab, India \\ *Corresponding author E-mail: pragyapgi80@ hotmail.com
}

\begin{abstract}
Background: Cancer patients face a number of problems, among those pain and fatigue are the most common. To manage pain and fatigue among cancer patients, studies now a days are even focusing on use of non-pharmacological/ non invasive methods as exercises, imagery etc. But studies on effect of progressive muscle relaxation (P.M.R) exercises on pain and fatigue among admitted patients are scarce.
\end{abstract}

Objective: The study was done to evaluate effectiveness of P.M.R exercises on pain and fatigue among hospitalized cancer patients receiving radiotherapy.

Methods: The study design was quasi-experimental Pre test Post test control group design. Total of 100 participants, 50 in each intervention and control group were included. The subjects in the intervention group received four P.M.R exercise sessions in 4weeks along with routine treatment while subjects in control group received treatment as usual with no added intervention.

Results: There was significant difference $(\mathrm{p}<0.01)$ in Pain scores Pre N.P.R.S $(4.42 \pm 2.35)$ to post N.P.R.S (3.44 \pm 2.05$)$ scores among intervention group (P.M.R). Pre assessment mean fatigue scores (C.F.S) of subjects were $33.80 \pm 10.62$ in intervention group (P.M.R) and 33.24 \pm 7.02 in controls where as post assessment C.F.S scores were $28.52 \pm 12.74$ and $36.52 \pm 7.53$ in intervention and control group respectively. There was significant $(\mathrm{p}<0.01)$ reduction in pre to post C.F.S in P.M.R group while fatigue increased significantly $(\mathrm{p}<0.01)$ in control group.

Conclusion: P.M.R along with routine standard treatment is effective in reducing pain and fatigue among hospitalized cancer patients receiving radiotherapy.

Keywords: Progressive muscle relaxation, Pain, Fatigue, cancer patients.

\section{Background}

Cancer patients face a number of problems, of which pain and fatigue are the most common problems, faced by almost all the cancer patients. Prevalence of pain is very high among hospitalized cancer patients. Estimates suggest that up to $79 \%$ of hospitalized cancer patients' experience pain [1]. Despite use of analgesics 51\% patients experience episodes of breakthrough pain [2] and up to $46 \%$ have moderate to severe pain[3,4]. Pain being the $5^{\text {th }}$ vital sign is very important to be assessed and managed in cancer patients also [5]. Minimizing pain among cancer patients will help to reduce suffering to a great extent and let cancer patients live a good quality of life. Fatigue is also one of the most common symptoms among patients with cancer.

Cancer related fatigue is a distressing, persistent, subjective sense of tiredness or exhaustion that occurs in $70-100 \%$ of cancer patients receiving radiotherapy or chemotherapy [6]. Its severity increases to a very high extent. Its prevalence is $75 \%$ to $90 \%$ in those receiving chemotherapy and $65 \%$ in those receiving radiotherapy [7]. According to American 
cancer society, $90 \%$ of patients in cancer treatment experience fatigue that can range from mild lethargy to feeling completely wiped out. It affects the quality of life, interferes with ability to work, relationships with others, physical and emotional well-being. Now-a-days there has been growing interest in managing these symptoms with nonpharmacological treatments [8]. Piper et al conducted a study on role of oncology nurses in translating National comprehensive cancer Network (N.C.C.N) assessment guidelines into practice. The article reviewed NCCN guidelines for cancer related fatigue assessment (C.R.F). Case studies done reflected the vital roles that oncology nurses can play in managing patient with C.R.F. The study also emphasized on viewing C.R.F as "sixth vital sign". Nurses are often confronted with patient's fatigue and are aware of its effects on the patient's daily life [9].

Managing for the problems of pain and fatigue among cancer patients can help a lot to improve their Quality of life. For this nurses are in best position to help out cancer patients by using some non-invasive techniques. According to the cancer pain management guidelines of comprehensive cancer network, cognitive behavioral coping strategies are recommended as an adjuvant to analgesic medicines [10]. Moreover patients also prefer non pharmacological methods for management of problems over pharmacological methods [8]. Progressive muscle relaxation (P.M.R) being one of the non invasive techniques, can be of great help.

P.M.R, is one of the cognitive behavioral coping strategies which have been found beneficial in cancer patients also $[11,12]$. Relaxation is a state of freedom from anxiety and skeleton muscle tension. Pain exacerbating thoughts get diminished and reduce perception of pain. "American Pain Society" quality of care task force for treatment of acute and chronic cancer pain had recommended relaxation, deep breathing, walking, imagery or visualization under nonpharmacological methods for cancer pain relief [13]. It is the patients' intentional work on muscles and a heightened sense of relaxation through muscles which is perceived as relaxation. Reeves et al. [14] explained the importance of physical interventions such as changes in patient positioning, relaxation techniques and energy conservation techniques for fatigue in patients with cancer pain. P.M.R is very easy, so it is widely used as basic relaxation technique. Relaxation techniques have been used for palliation of uncomfortable symptoms, mental support and self control of patients with cancer. Though few studies have seen its effect on fatigue, sleep [15], anxiety and Q.O.L [16] but P.M.R has been very scarcely tested for its effectiveness in reducing pain and fatigue among cancer patients receiving radiotherapy. The findings of a systematic review have suggested that exercise and increased physical activity in cancer patients improves function, quality of life, strength, endurance, and reduced depression, nausea, and pain [17].

A research study was conducted in Turkey on effects of relaxation on sleep quality and fatigue among 27 breast cancer patients undergoing adjuvant chemotherapy. The findings of the study revealed that P.M.R improved sleep quality and reduced fatigue in breast cancer patients [15].

Few of the researches have been carried out to assess and manage fatigue among cancer patients. But very few have seen effect of P.M.R on fatigue. A review published had evaluated 41 studies, of these 17 looked at activity based interventions, as home based exercises by cancer patients. 24 studies evaluated psychological interventions as group therapy, telephone counseling on stress management and relaxation training. Jacobson and his colleagues found that patients who received either of the two types of interventions reported less fatigue than control group patients [18]. A latest review article on nursing intervention for fatigue during cancer treatment from 1995 to 2005 produced 18 studies. Studies dealt with sleep promotion through instruction and education, exercise, distraction and relaxation. Significant effects were found in studies including exercise, a positive effect of education and counseling on sleep while distraction and relaxation were found effective only for few hours after intervention [16].

Overall the results of studies on effectiveness of P.M.R are ambiguous, so the present study was carried out with the aim of producing research-based evidence on effectiveness of P.M.R on pain and fatigue among cancer patients receiving radiotherapy.

\subsection{Operational definitions}

\subsubsection{Progressive muscle relaxation}

Refers to 30 minutes session for progressive contraction and relaxation of muscles of the body from head to toe by cancer patients, as per the instructions by the researcher and tape recorder.

\subsubsection{Pain}

Pain refers to the unpleasant sensory and emotional experience perceived by the cancer patients may be either due to cancer, its complications or complications of treatment as measured on Numerical pain rating scale (N.P.R.S).

\subsubsection{Fatigue}

Fatigue refers to the persistent feeling of weakness or tiredness among cancer patients interfering their usual functioning as measured on cancer fatigue scale. 


\section{Methodology}

\subsection{Research design}

The study was carried out using Quasi experimental, pre test-post test-control group design. Subjects were enrolled from NABH accredited and ECHS empanelled Cancer super specialty hospital in Mohali, Punjab, India from April 2010 to November 2011.

\subsection{Subjects}

A total number of 124 hospitalized cancer patients receiving radiotherapy were screened for inclusion in study. Out of 124 patients, 24 got excluded (not able to communicate, more than 80 years, terminally ill etc). Only 100 patients meeting inclusion criteria included in study, 50 in each intervention and control group.

\subsection{Ethical considerations}

Ethical approval was obtained before conducting research. The Medical superintendent, Nursing superintendent of the hospital and staff of radiation ward had been informed about the research study. Written informed consent was obtained from all study subjects after explaining that their non-participation will not affect the treatment in any way and they can quit from participation in the study at any time. In the end the subjects in control were also taught relaxation exercises after post assessment.

Inclusion criteria- Participants were included only if they were

1. In the age range of $18-79$ years.

2. Hospitalized and receiving radiotherapy for treatment of cancer.

3. Verbalized pain and fatigue in pre assessment.

Exclusion criteria-Patients were excluded from participation in the study if they were

1. Not willing to participate in the study.

2. Terminally ill.

3. Having any type of cognitive or communication problems.

4. Receiving chemotherapy or have undergone surgery within last 1 month

To avoid the contamination of study, all the enrolled subjects admitted in the unit received same intervention as randomly drawn by an independent person among the slips for intervention and control groups. The same intervention (P.M.R) was followed until a group of 25 patients' completely received the intervention and got discharged. In this way to complete a group of 50 patients' of a particular intervention group, intervention got repeated twice which enhanced the number of randomized assignment. In this way by the end, 50 subjects automatically received intervention while 50 subjects of control received usual treatment. Subjects in the intervention group attended progressive muscle relaxation exercise sessions while subjects in control group received usual treatment with no added intervention session.

\section{Instruments}

The demographic and disease related information of subjects was obtained on Patient information performa.

\section{Pain assessment}

Pain was rated on Numerical pain rating scale (N.P.R.S) by cancer patients' before and four (4) weeks after the intervention. N.P.R.S is a standardized tool for assessment of pain intensity among patients [19]. The reliability of tool for assessment of pain was calculated. The value of Pearson's correlation coefficient ( $r$ ) was 0.92 . The scale contains a $10 \mathrm{~cm}$ long line with scores ranging from 0 to 10 . The line is equally divided in 10 equal points with numeric's displayed from 0 to 10 . A score of 0 on the scale indicated no pain while a score of 10 indicated maximum possible pain. In the study it measured pain intensity among cancer patients in pre assessment and post assessment (after 4weeks). Pain intensity was easily marked on the scale by the cancer patients before and four (4) weeks after the intervention.

\subsection{Fatigue assessment}

Cancer Fatigue scale (C.F.S) was used to assess the fatigue in cancer patients receiving radiotherapy. It is a valid, brief self rating scale designed to reflect nature of fatigue. The scale consists of 15 items and three subscales: Physical, 
affective and cognitive fatigue. Each item is rated on a Likert scale from 1 (not at all) to 5 (very much). Patient can mark the number that describes the current state. The possible scores ranged from 0 to 28 for the physical, 0 to 16 for the affective and 0 to 16 for the cognitive subscale. The scale provides a total fatigue score ranging from 0 to 60 . The scale was developed by Okuyama and applied on cancer patients [20]. Hindi version was adapted by following standard procedure of adaptation. The reliability of tool for assessment of pain was calculated. The value of Cronbach's alpha was 0.89 .

\subsection{Intervention}

The progressive muscle relaxation exercises used in the study involved progressive contraction and relaxation of muscles of the body from head to toe performed by the cancer patients' in the lying down position on bed, as per the instructions by the researcher and tape recorder. Researcher also received training in P.M.R from an expert, renowned psychologist who has already dealt in relaxation and had research experience in the area. Similar tape was used for training and in all four P.M.R sessions. Subjects receiving relaxation intervention were first trained in doing progressive muscle relaxation exercises, which most of the patients' learnt in two to three trials. First session was then started. Patients were told to do P.M.R daily, for 15 to 20 minutes in between the weekly session. Total of four (4) sessions were arranged within 6weeks time for a group of 25 patients. As a result twelve (12) weeks time was taken for completing intervention for a group of 50 patients in intervention group. In the same way twelve (12) weeks time was taken to complete control group, which received usual treatment. Intervention involved in P.M.R group were as follows-

\subsubsection{Pre intervention Assessment}

Baseline assessment of pain (N.P.R.S) and fatigue (C.F.S) was done among study subjects in both intervention and control group.

- All the patients in P.M.R group were first trained in doing muscle relaxation exercises in 2 to 3 practice sessions or as required according to individual need of patient.

\subsubsection{Intervention protocol}

- $\quad$ First session of P.M.R was carried out by using the audiotape and Instructions were given by the researcher.

- Total number of sessions arranged for each patient were four (4), each one (1) week apart. Patients were told to do P.M.R daily, for 15 to 20 minutes in between the weekly session. The session involved progressive contraction and relaxation of muscles of the body from head to toe as per instructions by researcher and tape recorder.

- The selected patients were made to lie down and follow instructions.

- Patients were instructed not to contract a particular muscle group having acute problem or advised for rest by oncologist.

- Audio tape included only verbal instructions with no music background.

- Same audiotape was used for training and conducting P.M.R sessions for all patients.

- Each session took around 30minutes. Total of six (6) weeks time was taken for completing intervention for 25 patients enrolled under the group and complete all 4 sessions.

- Participants in control group received usual treatment with no added intervention

\subsubsection{Post intervention Assessment}

Post assessment of pain (N.P.R.S) and Fatigue (C.F.S), at the completion of all four P.M.R sessions and not after each session among participants of both intervention and control group.

Note- Before pre and post assessment, it was ensured that patient had not taken any analgesic within few hours.

\subsection{Data collection}

Quiet and non-disturbing environment was maintained for providing the intervention and collecting the data in the radiotherapy unit of the hospital. Intervention was carried out in the time, when patients' were free from their routine care and ward rounds. 
The pre or baseline assessment of Pain and fatigue was done among subjects in both intervention and control group. The subjects in the intervention group were first trained in doing P.M.R and then four (4) progressive muscle relaxation exercise sessions were arranged for them while subjects in control group received treatment as usual. The four (4) sessions were taken, each one (1) week apart. Within six (6) weeks time, four (4) sessions of P.M.R were arranged for a group of 25 patients' enrolled at one time point, each one (1) week apart. The post assessment of pain was again done among subjects in both intervention and control group after completion of all four sessions after four (4) weeks. Participants in control group received usual treatment.

\subsection{Statistical analysis}

Data were represented in Mean $( \pm$ SD). Demographic and disease or treatment related information was analyzed using chi square tests. Pre to Post comparison of N.P.R.S and C.F.S was done by paired t test. Data were analyzed using MS Excel and SPSS 16.0 software.

\section{Results}

\subsection{Demographic variables}

Table 1, depicts distribution of study subjects according to the demographic variables. Majority that is $64 \%$ from the Intervention group and 56\% from control group were 60 to 80 years old. In intervention group 54\% were males while in control group $44 \%$ were males. Majority of participants in both the groups were from Punjab that is $40 \%$ in P.M.R group and $44 \%$ in control group. It also has been found that $60 \%$ subjects in intervention group and $66 \%$ in control group were having qualification below Matric. Most of the subjects (52\%) in intervention group were servicemen or exserviceman while in control group, $60 \%$ were homemaker. Majority of subjects $58 \%$ in intervention group and $62 \%$ in control group were doing moderately heavy work. In intervention group 52\% while in control group, 56\% were earning between 5000 to 10,000 .

Study subjects in both the groups were homogenous according to the age, gender, domicile, Education, nature of work and monthly income.

\subsection{Disease related variables}

Table 2, depicts distribution of study subjects according to the disease related variables. In intervention group $46 \%$ while in control group $64 \%$ were having cancer of reproductive and genitourinary system. Majority of subjects in intervention group (56\%) and control (54\%) had stage 2 cancers. In intervention group $74 \%$ while in control group $58 \%$ subjects were having duration of illness between 6 months to 12 months. There were no significant differences in disease related characteristics of subjects in both the groups.

\subsection{Comparison of Mean Pain and fatigue scores}

Table 3 depicted, Pre to Post assessment comparison of Mean Pain (N.P.R.S) and Fatigue (C.F.S) scores among study subjects. Paired t test was applied to compare the means. There was significant difference $(\mathrm{p}<0.01)$ in Pre N.P.R.S (4.42 \pm 2.35$)$ to post N.P.R.S (3.44 \pm 2.05$)$ scores among subjects in intervention group (P.M.R). There was no significant difference in Pre N.P.R.S (4.06 \pm 1.80$)$ to post N.P.R.S $(4.62 \pm 1.88)$ scores in control group.

Pre assessment mean fatigue scores (C.F.S) of subjects were 33.80 \pm 10.62 in intervention group (P.M.R) and 33.24 \pm 7.02 in control group where as post assessment mean fatigue scores were $28.52 \pm 12.74$ and $36.52 \pm 7.53$ in intervention and control group respectively. There was significant difference $(\mathrm{p}<0.01)$ in pre to post assessment fatigue scores in intervention group (P.M.R) as well as control group.

Pain and fatigue scores decreased among subjects in intervention group, while fatigue scores increased among subjects in control group after four (4) weeks. P.M.R along with routine treatment is effective in reducing pain and fatigue in cancer patients. 
Table 1: Distribution of Study Subjects according to Demographic Variables.

\begin{tabular}{|c|c|c|c|c|}
\hline Variables & $\begin{array}{l}\text { Intervention Group } \\
(\mathrm{N}=50) \\
\mathrm{f}(\%)\end{array}$ & $\begin{array}{c}\text { Control Group } \\
(\mathrm{N}=50) \\
\mathrm{f}(\%)\end{array}$ & $\chi^{2}$ & p-value \\
\hline $\begin{array}{l}\text { Age (Years) } \\
18-38 \\
39-59 \\
60-80\end{array}$ & $\begin{array}{ll}1 & (2) \\
17 & (34) \\
32 & (64)\end{array}$ & $\begin{array}{l}1(2) \\
21(42) \\
28(56)\end{array}$ & 0.38 & .54 \\
\hline $\begin{array}{l}\text { Gender } \\
\text { Male } \\
\text { Females }\end{array}$ & $\begin{array}{ll}27 & (54) \\
23 & (46) \\
\end{array}$ & $\begin{array}{l}22(44) \\
28(56) \\
\end{array}$ & 1.0 & .31 \\
\hline $\begin{array}{l}\text { Domicile } \\
\text { Himachal Pradesh } \\
\text { Punjab } \\
\text { Haryana } \\
\text { Others }\end{array}$ & $\begin{array}{ll}19 & (38) \\
20 & (40) \\
8 & (16) \\
3 & (6) \\
\end{array}$ & $\begin{array}{l}19(38) \\
22(44) \\
7(14) \\
2(4)\end{array}$ & 0.30 & .86 \\
\hline $\begin{array}{l}\text { Education } \\
\text { Below Matric } \\
\text { Matric } \\
\text { Intermediate } \\
\text { >Graduate }\end{array}$ & $\begin{array}{l}30(60 \%) \\
16(32 \%) \\
04(8 \%) \\
\quad-\end{array}$ & $\begin{array}{l}33(66 \%) \\
15(30 \%) \\
02(4 \%) \\
\quad-\end{array}$ & 0.84 & .65 \\
\hline $\begin{array}{l}\text { Occupation status } \\
\text { Labourer } \\
\text { Housewife } \\
\text { Service or Ex-service } \\
\text { Business }\end{array}$ & $\begin{array}{ll}2 & (4) \\
22 & (44) \\
26 & (52) \\
- & \end{array}$ & $\begin{array}{l}6(12) \\
30(60) \\
13(26) \\
1 \quad(2)\end{array}$ & 5.04 & $.02^{\mathrm{a}}$ \\
\hline $\begin{array}{l}\text { Nature of work } \\
\text { Sedentary } \\
\text { Moderate } \\
\text { Heavy }\end{array}$ & $\begin{array}{ll}16 & (32) \\
29 & (58) \\
5 & (10)\end{array}$ & $\begin{array}{ll}15 & (30) \\
31 & (62) \\
4 & (8)\end{array}$ & 1.54 & .21 \\
\hline $\begin{array}{l}\text { Financial Status } \\
<5000 \\
5001-10000 \\
10001-15000 \\
>15000\end{array}$ & $\begin{aligned} 9 & (18) \\
26 & (52) \\
13 & (26) \\
2 & (4)\end{aligned}$ & $\begin{array}{ll}8 & (16) \\
28 & (56) \\
11 & (22) \\
3 & (6) \\
\end{array}$ & 0.16 & .92 \\
\hline
\end{tabular}

${ }^{\mathrm{a}} \mathrm{p}<0.05$ Significant difference

Table 2: Distribution of Study Subjects according to Disease Related Variables

\begin{tabular}{|c|c|c|c|c|}
\hline Variables & \begin{tabular}{|c|} 
Intervention Group \\
$(\mathrm{N}=50)$ \\
$\mathrm{f} \quad(\%)$ \\
\end{tabular} & $\begin{array}{c}\text { Control Group } \\
(\mathrm{N}=50) \\
\mathrm{f} \quad(\%)\end{array}$ & $\chi^{2}$ & p-value \\
\hline $\begin{array}{l}\text { Site of Cancer } \\
\text { Gastrointestinal } \\
\text { Reproductory \& Genitourinary } \\
\text { Blood and Circulatory } \\
\text { Respiratory \& ENT } \\
\text { Other }\end{array}$ & $\begin{array}{ll}8 & (16) \\
23 & (46) \\
3 & (6) \\
11 & (22) \\
5 & (10) \\
\end{array}$ & $\begin{array}{ll}9 & (18) \\
32 & (64) \\
2 & (4) \\
6 & (12) \\
1 & (2)\end{array}$ & 5.10 & .07 \\
\hline $\begin{array}{l}\text { Stage of cancer } \\
\text { Stage } 0-1 \\
\text { Stage 2a-2b } \\
\text { Stage 3a-3b }\end{array}$ & $\begin{array}{ll}7 & (14) \\
28 & (56) \\
15 & (30) \\
\end{array}$ & $\begin{array}{ll}7 & (14) \\
27 & (54) \\
16(32) \\
\end{array}$ & 0.04 & .83 \\
\hline $\begin{array}{l}\text { Duration of illness (months) } \\
<6 \\
6-12 \\
>12\end{array}$ & $\begin{array}{l}37(74 \%) \\
13(26 \%) \\
-\end{array}$ & $\begin{array}{ll}29 & (58 \%) \\
20 & (40 \%) \\
1 & (2 \%)\end{array}$ & 9.16 & .16 \\
\hline
\end{tabular}


Table 3: Comparison of Mean Pain (N.P.R.S) and Fatigue Scores (C.F.S) in Intervention and Control group

\begin{tabular}{|l|l|l|c|c|l|}
\hline Variables & Group & $\mathrm{n}$ & $\begin{array}{c}\text { Pre-Assessment } \\
\text { Mean } \pm \text { SD }\end{array}$ & $\begin{array}{c}\text { Post-Assessment } \\
\text { Mean } \pm \text { SD }\end{array}$ & p-value \\
\hline \multirow{2}{*}{$\begin{array}{l}\text { Pain } \\
\text { (N.P.R.S) }\end{array}$} & Intervention Group & 50 & $4.42 \pm 2.35$ & $3.44 \pm 2.05$ & $.002^{\mathbf{a}}$ \\
\cline { 2 - 7 } & Control Group & 50 & $4.06 \pm 1.80$ & $4.62 \pm 1.88$ & .06 \\
\hline $\begin{array}{l}\text { Fatigue } \\
\text { (C.F.S) }\end{array}$ & Intervention Group & 50 & $33.80 \pm 10.62$ & $28.52 \pm 12.74$ & $.005^{\mathbf{a}}$ \\
\cline { 2 - 7 } & Control Group & 50 & $33.24 \pm 7.02$ & $36.52 \pm 7.53$ & $.03^{\mathbf{b}}$ \\
\hline
\end{tabular}

${ }_{\mathrm{b}}^{\mathrm{a}} \mathrm{p}<.01$ Highly significant reduction of N.P.R.S and C.F.S score from Pre to Pro Intervention group.

${ }_{\mathrm{p}}^{\mathrm{p}}<.05$ Significant increase in C.F.S scores from Pre to Post control group.

\section{Discussion}

The present study was done to evaluate the effectiveness of P.M.R on pain and fatigue among hospitalized cancer patients' receiving radiotherapy. Though in few studies, researchers have assessed effect of P.M.R on variables such as stress, anxiety, fatigue, depression and quality of life [21,22], but there is limited literature available on hospitalized cancer patients receiving radiotherapy assessing effect of P.M.R on pain and fatigue.

The participants of both control and intervention group were homogenous. There was no significant difference in their demographic and disease related characteristics.

In this study, total of four P.M.R sessions were arranged within six (6) weeks time for a group of 25 patients, after training them in doing P.M.R. Most of the patients learned doing P.M.R in 2 to 3 sessions. The patients were told to practice P.M.R twice in a day. Each session lasted for 20-30 minutes. In other studies also P.M.R sessions have been taken for maximum of 30 minutes [23]. This is due to the reason that complete relaxation procedure for all muscle groups takes up to 20 minutes and some time is also required for making the patient to assume relaxed position.

Initially some of the difficulties were faced in training the patients for doing P.M.R. All the patients enrolled at one point of time were taught P.M.R first and then each patient was assessed for learning. Again the patients were corrected for their mistakes. Every patient required minimum of two practice sessions to learn P.M.R thoroughly. A recent study done in Japan, have also assessed the experiences of difficulty that patients faced in learning P.M.R [21]. But in present study once patients learned doing P.M.R, they reported it to be easy to perform even when they are tired and can not go for a walk.

The immediate effect of P.M.R was not assessed rather the effect was observed after four (4) weeks on completion of all four P.M.R sessions. This was done to observe intermediate and not the immediate effect of P.M.R. As its immediate effect has already been seen [24].

The audio for P.M.R used in the study did not included music. In this study the researcher wished to assess effect of P.M.R alone, which could have been biased by effect of music. For the same reason P.M.R was not combined with interventions as guided imagery. In other studies researchers have used P.M.R alone or in combination with other interventions as Guided imagery, hypnosis etc. [25].

In the present study, P.M.R was found effective in reducing pain as well as fatigue among cancer patients'. At the beginning both the groups were homogenous according to their Mean pain and fatigue scores. But after four (4) weeks the patients in intervention group had significant decrease in their mean pain and fatigue scores. But the findings of other studies on P.M.R are ambiguous. An analysis of Literature review on P.M.R and imagery interventions for cancer pain reported that interventions reduced sensory experience of pain but had no effect on functional status of patients [26]. One study done on individual difference variables and the effects of P.M.R and analgesic imagery on cancer pain among 40, hospitalized cancer patients in U.S.A, revealed that only half of the participants achieved a clinically meaningful improvement in pain with each intervention [21]. No other studies have seen the effect of P.M.R on pain among cancer patients.

For fatigue effect of relaxation was observed only for few hours of intervention [16]. Though few studies have seen the effect of exercise on fatigue but studies on effect of P.M.R and fatigue among cancer patients are not available. Among the patients of control group, increase in fatigue was found after four (4) weeks. The rise in fatigue is due to the oxidative stress produced in the body during radiotherapy [27, 28]. The findings of present study are leading to the conclusion that P.M.R is effective in reducing pain and fatigue among cancer patients receiving radiotherapy. 


\section{Nursing implications}

The findings of study recommend use of progressive muscle relaxation exercises to reduce perception of pain and fatigue among cancer patients. This will help to reduce pain and fatigue and thus improve Quality of life to a great extent in cancer patients.

\section{Limitations}

Subjects were enrolled from one hospital to reduce bias due to different hospital settings and staff. But on the other hand it minimizes the generalizations of the study findings.

\section{References}

[1] McMillan SC, Tittle M, Hagan S, et al. Management of pain and pain-related symptoms in hospitalized veterans with cancer. Cancer Nurs. 2000;23(5):327-336.

[2] Portenoy RK, Payne D, Jacobsen P. Breakthrough pain: characteristics and impact in patients with cancer. Pain. 1999;81:129-134.

[3] Wells N. Pain intensity and pain interference in hospitalized patients with cancer. Oncol Nurs Forum.2000;27:985-991.

[4] McNeill JA, Sherwood GD, Starck PL, et al. Assessing clinical outcomes: patient satisfaction with pain management. J Pain Symptom Manage. 1998;16(1):29-40

[5] Mularski RA, White-Chu F, Overbay D, et al. Measuring Pain as the 5th Vital Sign Does Not Improve Quality of Pain Management. J Gen Intern Med. 2006;21(6):607-612.

[6] Agasi-Idenburg C, Velthuis M, Wittink H. Quality criteria and user-friendliness in self-reported questionnaires on cancer-related fatigue: a review. J Clin Epidemiol. 2010;63(7):705-711.

[7] Stone P. The measurement, causes and effective management of cancer-related fatigue. Int J Palliat Nurs. 2002;(3):120-128.

[8] Jacobsen PB, Donovan KA, Vadaparampil ST, et al. Systematic Review and Meta-Analysis of Psychological and Activity-Based Interventions for Cancer-Related Fatigue. Health Psychol. 2007; 26(6):660-667.

[9] Piper BF, Borneman T, Sun VC, et al. Cancer-related fatigue: role of oncology nurses in translating National Comprehensive Cancer Network assessment guidelines into practice. Clin J Oncol Nurs. 2008;12(5 Suppl):37-47.

[10] National Comprehensive Cancer Network. (2009). NCCN Clinical Practice GuidelinesTM: Adult cancer pain [v.1.2009]. Retrieved January 7, 2012, from http://www.nccn.org/professionals/physician_gls/PDF/pain.pdf

[11] Lolak S, Connors GL, Sheridan MJ, et al. Effects of progressive muscle relaxation training on anxiety and depression in patients enrolled in an outpatient pulmonary rehabilitation program. Psychother Psychosom. 2008;77(2):119-125.

[12] Marcus AC, Garrett KM, Cella D, et al. Can telephone counseling post-treatment improve psychosocial outcomes among early stage breast cancer survivors? Psychooncology. 2010;19(9):923-932.

[13] Gordon DB, Dahl JL, Miaskowski C, et al. American pain society recommendations for improving the quality of acute and cancer pain management: American Pain Society Quality of Care Task Force. Arch Intern Med. 2005;165(14):1574-1580.

[14] Reeves K. A cancer pain primer. Medsurg Nurs. 2008;17(6):413-419; quiz 420.

[15] Demiralp M, Oflaz F, Komurcu S. Effects of relaxation training on sleep quality and fatigue in patients with breast cancer undergoing adjuvant chemotherapy. J Clin Nurs. 2010;19(7-8):1073-1083.

[16] De Nijs EJ, Ros W, Grijpdonck MH. Nursing intervention for fatigue during the treatment for cancer. Cancer Nurs. 2008;31(3):191-206.

[17] Barbaric M, Brooks E, Moore L, et al. Effects of physical activity on cancer survival: a systematic review. Physiother Can. 2010;62(1):25-34.

[18] Jacobsen PB, Donovan KA, Vadaparampil ST, et al. Systematic review and meta-analysis of psychological and activity-based interventions for cancer-related fatigue. Health Psychol. 2007;26(6):660-667.

[19] McCaffery M, Beebe A. Pain: Clinical Manual for Nursing Practice. Baltimore: V.V. Mosby Company; 1993.

[20] Okuyama T, Akechi T, Kugaya A, et al. Development and validation of the cancer fatigue scale: a brief, three-dimensional, self-rating scale for assessment of fatigue in cancer patients. J Pain Symptom Manage. 2000;19(1):5-14.

[21] Kwekkeboom KL, Wanta B, Bumpus M. Individual difference variables and the effects of progressive muscle relaxation and analgesic imagery interventions on cancer pain. J Pain Symptom Manage. 2008;36(6):604-615.

[22] Jamadar KS. Effect of muscle relaxation on stress level on cancer breast patients. Nightingale Nursing Times. 2009 ; 5(5): $32-47$.

[23] Krajewski J, Wieland R, Sauerland M. Regulating strain states by using the recovery potential of lunch breaks. J Occup Health Psychol. 2010;15(2):131-139.

[24] Sheu S, Irvin BL, Lin HS, et al. Effects of progressive muscle relaxation on blood pressure and psychosocial status for clients with essential hypertension in Taiwan. Holist Nurs Pract. 2003;17(1):41-47.

[25] Campos de Carvalho E, Martins FT, dos Santos CB. A pilot study of relaxation technique for management of nausea and vomiting in patients receiving cancer chemotherapy. Cancer Nurs. 2007;30(2):163-167.

[26] Wallace KG. Analysis of recent literature concerning relaxation and imagery interventions for cancer pain. Cancer Nurs. 1997;20(2):79-87.

[27] Sabitha KE, Shyamaladevi CS. Oxidant and antioxidant activity changes in patients with oral cancer and treated with radiotherapy. Oral Oncol. 1999; 35: 273-277.

[28] Kasapovic J, Pejic S, Todorovic A, et al. Antioxidant status in breast cancer patients of different ages after radiotherapy. Arch Biol Sci Belgrade 2009; 61: 23-28. 